\title{
Geothermal Power Plant Installation in Pakistan; Choice of Location, Inspecting its Potential and Utilization
}

\author{
Azfar Rasool, Farhana Umer*, Uzair Nazir, Aoun Muhammad, M. Shoaib Rabbani and M. Javed Hanif \\ Department of Electrical Engineering, Islamia University of Bahawalpur, Pakistan; \\ azfarrasool3123@gmail.com, farhana.umer@iub.edu.pk,uzair_engr@yahoo.com, \\ aoun.muhammad@iub.edu.pk, shoaibrabbani@live.com, javedhanif11@yahoo.com
}

\begin{abstract}
Objectives: The main emphasize is to locate the high potential gradient range (HPGR) for geothermal energy in Pakistan. Methods/Statistical Analysis: An engineering overview and analysis is mentioned for the installation of Geothermal Power Plant (GPP). It includes the hypothetical estimation for the HPGR geothermal energy to extract the amount of electrical power. These are obtained from North-Eastern region of China's geothermal energy fields. A comparison method technique is utilized to justify the geothermal fields of HPGR in Pakistan. Findings: The hot and dry rocks are the area of concern to build GPP technology of two phase binary cycle system. The preliminary estimation of working energy leads to the forecasting of the electric potential sites. A regressive result is determined for the power and energy in the forecast of 30 years for suitability; where energy efficiency, electrical power, production temperature, and heat extraction rates behaviors are found on the basis of 5 years preliminary data. The sole purpose is to utilize a green energy to meet the demand of energy crises in Pakistan. Application/Improvements: The alternate and renewable geothermal energy resource is in consideration for the generation of electricity. GPP installation is considered to be an inception for Pakistan and the ease in implementation will be provided by the Pak-China Economic Corridor, section of the Energy Sector Renewable Energy Projects. It will add up plentiful electrical power to the grids for use of commercial and non-commercial.
\end{abstract}

Keywords: Energy Extraction, Energy Inspection, Geothermal Energy, Plant Installation, Power Plant Technology, Renewable Energy

\section{Introduction}

Nowadays, Pakistan is facing severe energy crises. The electrical shortfall reaches up to 4000-5000 MW per day in summer with a peak demand of $17500 \mathrm{MW} \stackrel{1,2}{ }$. This gives us a constant blackouts and hampering the industrial and commercial business. Therefore, Geothermal Energy as an alternate source of energy is in consideration. It also acts as a greener and renewable resource of energy in comparison with the hydrocarbons ${ }^{3}$. Geothermal Power Plant provides 24/7 hours, a constant amount of electricity in comparison with the other renewable energy sources like solar and wind energy ${ }^{ \pm}$.
Pakistan is immensely rich in high potential geothermal energy. The earth skin Surface Temperature Gradient (STG) is in between $100-230^{\circ} \mathrm{C}$ in the northern areas of Pakistan like Murtazabad, Tatta Pani, Kotly, etc. Chagai (Baluchistan province) has STG around $200-300^{\circ} \mathrm{C}$ due to its active volcanic arc. The southern part of Indus Basin near Karachi has STG around $70-145^{\circ} \mathrm{C}$. Analysis Zaigham et al. checked the images of satellite survey as well as searched the already present oil and gas wells depths and found the high STG rate in Himalayan collision zone, Chagi District, Southern Part of Indus Basin inclusive of Karachi and Thar Desert which is depicted in Figure $1 \frac{5,6}{6}$.

${ }^{*}$ Author for correspondence 


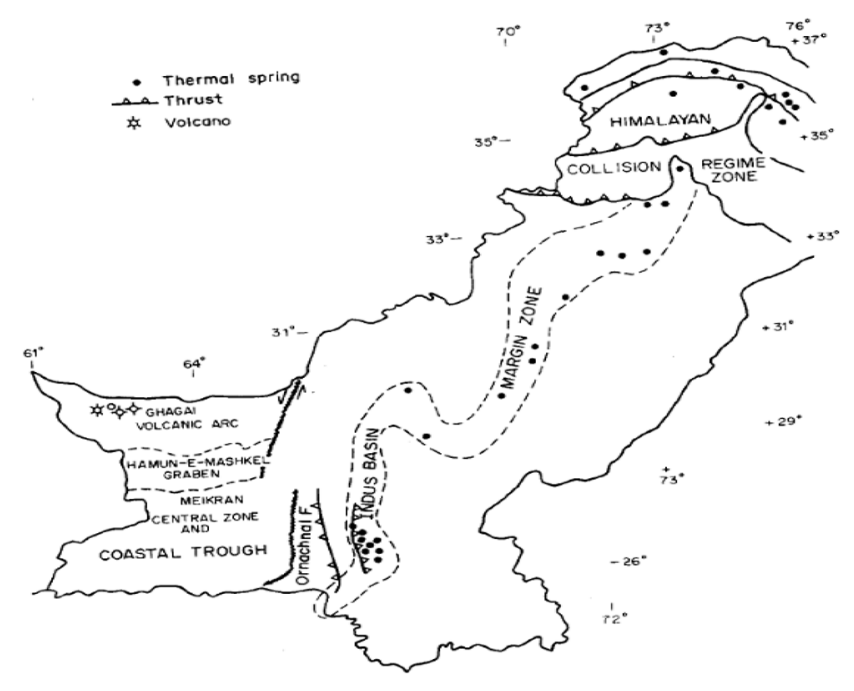

Figure 1. Geothermal areas of Pakistan ${ }^{25}$.

For an engineering view point, the Hot and Dry Rock (HDR) energy resources are available of high thermal gradient for about $3-4.5^{\circ} \mathrm{C} / 100 \mathrm{~m}$ in the southern part of Indus Basin and Karachi ${ }^{7}$. This region is seismically active as it lies on an epicenter of the Indo-Eurasian Plate and an average of 3-5 on Richter scale is on record as shown in Figure $2^{\frac{8}{*}}$. This part of Pakistan is a special interest for the installation of Geothermal Power Plant because the

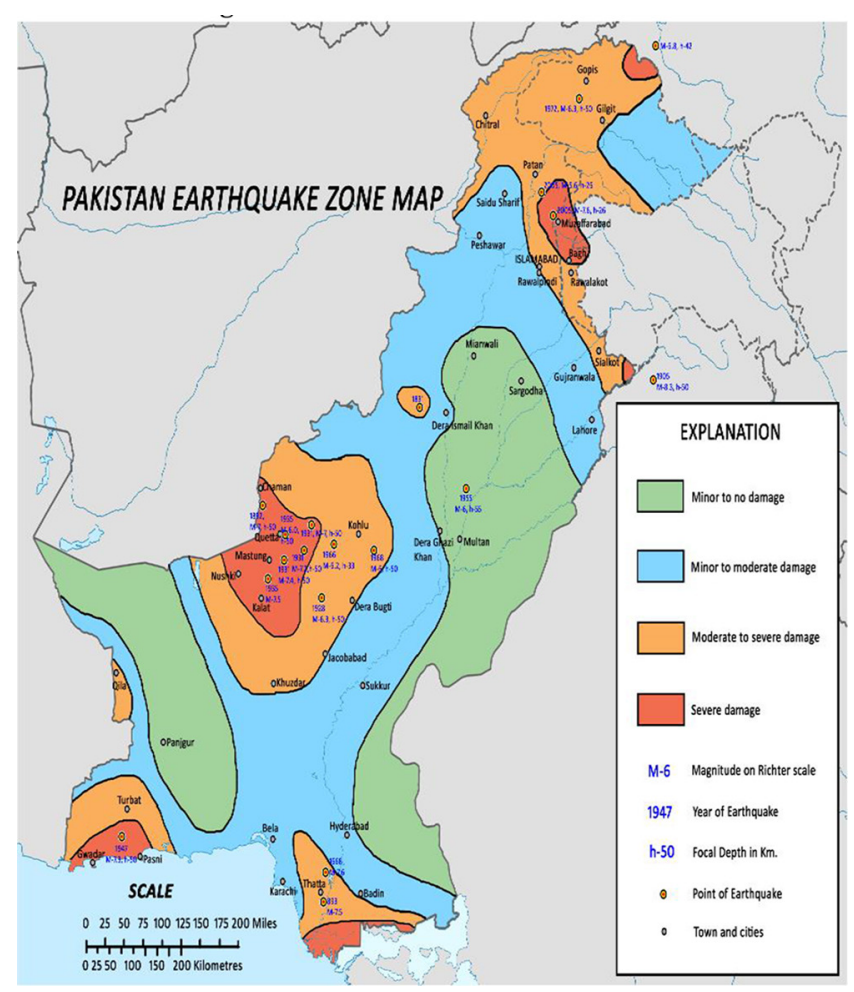

Figure 2. Seismically Active areas of Pakistan $\underline{26}$. thermal gradient is well enough to work for detail exploration and drilling. Moreover, the infrastructure facilities are attractive in southern Sindh to conduct detail survey and for the installation of Power Plant to generate electricity. Whereas, the other high thermal gradient areas of Pakistan are lacking the modern infrastructure facilities.

\section{Methodology}

Consider a Two Phase System of Geothermal Power Plant Technology in which the working fluid water is predominantly in use. Our interest is to find the electrical potential of any geothermal field where the power plant.

\subsection{Pressure Variations and Transmission}

Assuming a unit volume $\mathrm{V}$ of working fluid, down the well the saturation pressure state past is reached along the saturation curve?

$$
p=p_{s a t}(T)
$$

According to Gay-Lussac's Law the pressure $p$ will decrease when working fluid changes its state from water to steam by the heat from the porous rocks, the corresponding temperature $T$ tends to drop

$$
\Delta T=-\Delta p /\left(d p_{s a t} / d T\right)
$$

The volume will increase $\Delta V$, as the steam occupies more volume than water. The given drop in pressure $\Delta p$ enables the high compressibility $c_{2}$ to yield more working fluid from storage. Subscript 2 is used for compressibility which represents Two-Phase System only. Solving (2) for compressibility, by using the gas equations

$$
c_{2}=\frac{1}{V} \frac{\Delta V}{\Delta p}
$$

For the detail expression of compressibility, the associated densities of water $\rho_{w}$ and steam $\rho_{s}$, as well as enthalpies of water and steam phase $H_{w}$ and $H_{s}$ are in study. $\varnothing$, is the porosity of the medium and $\overline{\rho c}$ is the heat capacity of the wet rock. Solving (3) for the given parameters ${ }^{10,11}$.

$$
c_{2}=\left(\frac{1}{\varnothing}\right)\left(\frac{1}{H_{s}-H_{w}}\right)\left(\frac{\rho_{w}-\rho_{s}}{\rho_{s} \rho_{w}}\right)\left(\frac{\overline{\rho c}}{d p_{s a t} / d T}\right)
$$

It is noted that $\rho_{w}>\rho_{s}$ and $H_{s}>H_{w}$. From (4), it is also noted that the compressibility between the any of the phase does not play a subjective role, rather the transfer of 
working fluid between the phases is important. Because the working fluid in the pores respond to the pressure drop which creates the pressure gradient for the thermal flow of heat from the hot rocks towards the working fluid to enhance the conduction flow.

\subsection{The Source of the Extracted Energy}

Consider the specific well with uniform pressure $p$ and the uniform water saturation $S$ which is the ratio of water volume to total pore space available in a given area of well. The total dynamic viscosity of the working fluid is $\mu_{t}^{12}$.

$$
\mu_{t}=\frac{F_{w} S}{\mu_{w}}+\frac{F_{s} S}{\mu_{s}}
$$

Here, $F_{w} S$ and $F_{s} S$ are the working fluid saturation dependent relative permeability of the water and steam in the Two Phase System. Whereas, $\mu_{w}$ and $\mu_{s}$ are the dynamic viscosities of the water and steam respectively. The hydraulic diffusivity is represented by $\kappa$

$$
\kappa=k / \varnothing \mu_{t} c_{2}
$$

Now here, $\mathrm{K}$ is the permeability of the medium. And the pressure diffusion equation is given by

$$
\frac{1}{\kappa} \frac{\partial p}{\partial t}=\nabla^{2} p
$$

Assuming the transient flow of the working fluid be negligible to make ease in general calculations. The vertical geometric shape of the tube is most suitable with depth $h$ and the radius $r$. When substituting (5) in (6), it gives $\left(^{*}\right)$. Replacing $\left({ }^{*}\right)$ in $(7)$ and solve it according to

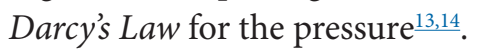

$$
p=\left(W v_{t} / 4 \pi \mathrm{k} h\right)\left(-E i\left(-r^{2} / \kappa t\right)\right)
$$

For time $t$, the constant mass rate $W$, energy is $E$ and the reservoir flow impedanceis given by $i$.

$$
i=\frac{p_{\text {inj }}-p_{\text {pro }}}{q}
$$

Production flow rate is $q$ and the bottom hole pressure of injection well and the production well is represented by $p_{i n j}$ and $p_{p r o}$ respectively.
The total kinematic viscosity $v_{t}$ is related by kinematic viscosities of the independent two phase of water $v_{w}$ and steam $v_{s}$

$$
\frac{1}{v_{t}}=\frac{F_{w} S}{v_{w}}+\frac{F_{s} S}{v_{s}}
$$

Rearranging (8) and separating for energy, we get

$$
E=\frac{4 \pi \mathrm{k} p \kappa h t}{W v_{t} i r^{2}}
$$

This energy is extracted from the rock in the form of heat which gives high enthalpies for the mixture of steam and water. The yield of energy depends upon the flow rate of the working fluid directly. Thus, the potential of the geothermal field can be determined and the standard recommended values range is given in Table 1.

Table 1. Recommended Standard Values Range of the Two Phase Binary System for the extraction of Energy ${ }^{27}$

\begin{tabular}{|c|c|}
\hline Specifications & $\begin{array}{c}\text { Recommended } \\
\text { Standard Values Range }\end{array}$ \\
\hline Pressure (bar) & $2-13$ \\
\hline Temperature $\left({ }^{\circ} \mathrm{C}\right)$ & $100-350$ \\
\hline Enthalpy of Water $(\mathrm{KJ} / \mathrm{g})$ & $2.1-2.8$ \\
\hline $\begin{array}{c}\text { Vertical Height of Tube }(\mathrm{m}) \\
\text { Heat Transfer Coefficient } \\
\left(\mathrm{W} / \mathrm{m}^{\circ} \mathrm{C}\right)\end{array}$ & $200-300$ \\
\hline $\begin{array}{c}\text { Utilization Efficiency of } \\
\text { Binary System }(\%)\end{array}$ & $1020-1140$ \\
\hline
\end{tabular}

\section{Results}

The Binary Cycle System for the Geothermal Power Plant Technology has thermal efficiency $\eta_{\text {therm }}$ is up to $50 \%$ and it could be more than this value for larger Geothermal Power Plant $t^{15}$. Thus, the extracted energy (11) becomes half of its value. The losses of the alternator for such kind of large scale power plants are in between the range of $(1-2) \% \frac{16}{16}$. Therefore, the mechanical power $P_{m}$ available on the turbine in the working fluid estimates the amount of electric potential in the form of electrical power $P_{e}=1 \%$ $P_{m}$, and from (11), it is given as

$$
P_{m}=\frac{2 \pi \mathrm{k} p \kappa h}{W v_{t} i r^{2}}
$$


The efficiency of the pump $\eta_{p}$ is round about $80 \% \frac{17}{17}$. So, the power consumed by the pump will be subtracted from (12) to determine the net efficiency of a geothermal power plant. A 30 year time span trend is shown for the energy efficiency of the power and the performance of heat pump. The statistical data is the survey analysis of the north-eastern part of China's geothermal fields. It also includes the forecasted result based on a survey work which is depicted in Figure $3 \frac{18}{}$.

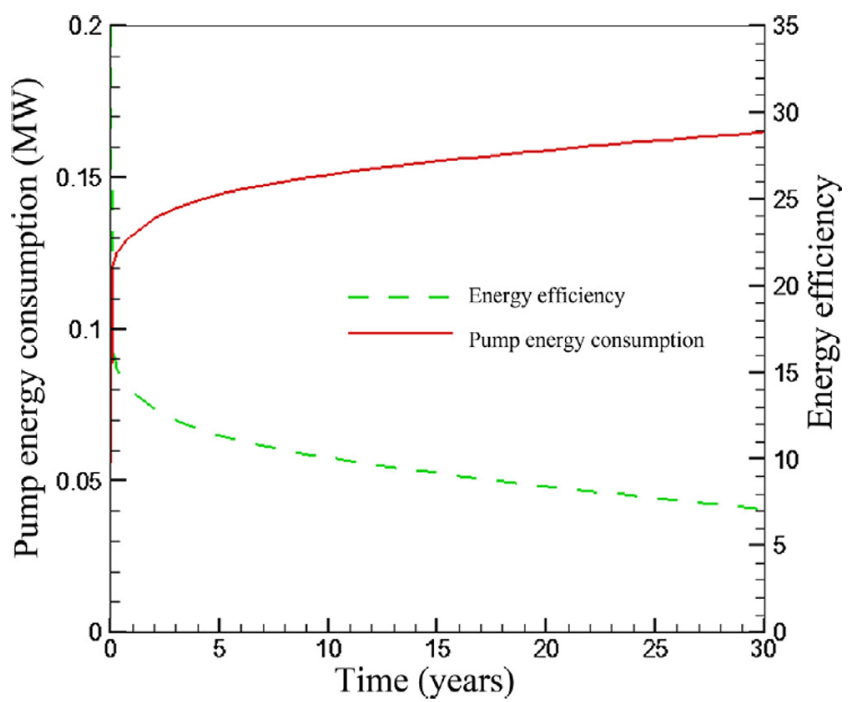

Figure 3. Forecast on behavior of pump and energy efficiency.

In a similar fashion, we can calculate the heat extraction rate by using (11) to judge the geothermal field potential for the production of electricity. Even the low

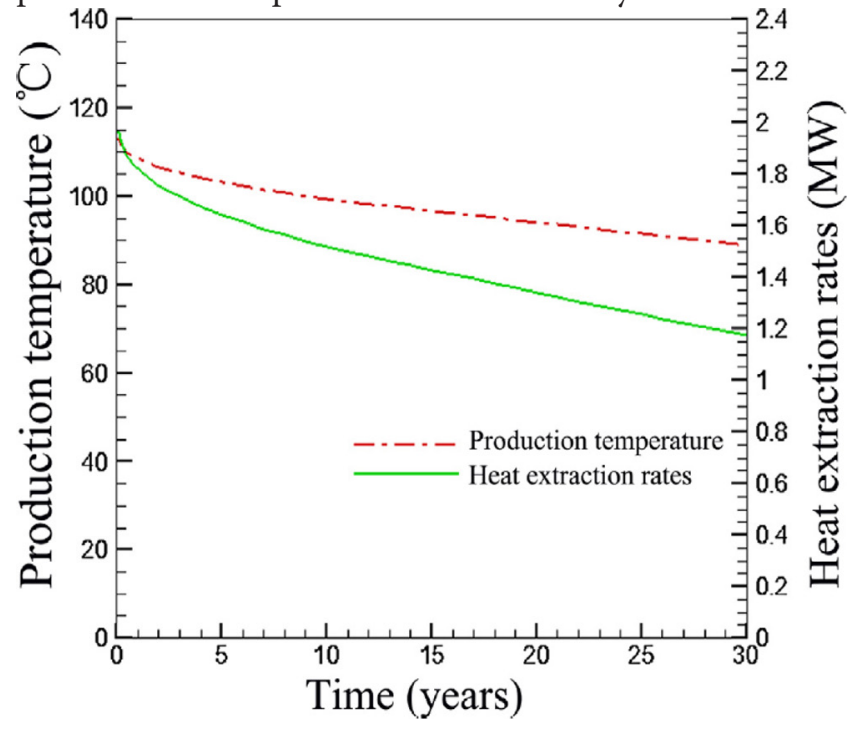

Figure 4. Forecast behavior of heat extraction rate and comparison with production temperature.
Table 2. Pre-regression data of 5 years for the forecaster of 30 years

\begin{tabular}{|c|c|c|c|c|}
\hline Year & $\begin{array}{c}\text { Production } \\
\text { Temperature } \\
\left({ }^{\circ} \mathrm{C}\right)\end{array}$ & $\begin{array}{c}\text { Pump } \\
\text { Consumption } \\
(\mathrm{MW})\end{array}$ & $\begin{array}{c}\text { Heat } \\
\text { Extraction } \\
\text { Rate } \\
(\mathrm{MW})\end{array}$ & $\begin{array}{c}\text { Energy } \\
\text { Efficiency } \\
(\%)\end{array}$ \\
\hline 1 & 111.2 & 0.12 & 1.98 & 15.8 \\
\hline 2 & 109.7 & 0.132 & 1.81 & 13.9 \\
\hline 3 & 108.3 & 0.137 & 1.73 & 13.0 \\
\hline 4 & 106.9 & 0.141 & 1.67 & 11.9 \\
\hline 5 & 105.6 & 0.144 & 1.64 & 11.3 \\
\hline
\end{tabular}

temperature $<150^{\circ} \mathrm{C}$ geothermal fields can also give considerable potential for a specific geothermal unit. As indicated and forecasted by Chinese on a basis of survey work to have ample data to make confident predictions. Likewise, 30 years trend shows in Figure 4, for the extraction of heat with respect to temperature gradients. The real progressive data is undermined in Table 2 for 5 years to generate results on the basis of regression technique for the forecasting 19,20 .

\section{Discussion}

Pakistan is declared as a tax free zone for the installation of renewable energy power plants from 2006. The import and custom duty taxes on machinery and its equipment are also exempted. Moreover, the sales taxes are also excluded on the import of renewable energy sector machineries ${ }^{21}$. The main reason is to attract the local and foreign investors to take part in removing the energy crises of Pakistan in a greener way.

An individual work was carried out for the exploration of geothermal fields in a past by different organizations and among them The United Nations University work was on top of list which was carried long time ago in $1998^{22}$. There is a need to conduct a detail surveys based on an installation of geothermal power plants. Whereas, the government of Pakistan is not taking a keen interest to develop a geothermal energy for the production of electricity. Even the Alternate Energy Development Board (AEDB) working under the Ministry of Water and Power of government of Pakistan does not include it yet as a long term planning scheme ${ }^{23}$. The non-renewable resources are depleting day by day at a huge rate of natural gas, coal and oil and yet the Pakistani government has not installed any 
geothermal power plant except the 50MW wind energy plant in $\operatorname{Sindh}^{24}$.

Pakistan has got an enormous geothermal potential for the production of electricity. The government has feasible and relaxing policies for the local and foreign investors in building of geothermal power plants. But the series of obstacles come in a way like unawareness about the geothermal energy potential in Pakistan and an extremely high installation cost. Nevertheless, once the power plant is installed at any particular geothermal active field, it will give a cheap amount of electricity for rest of the life. Provided that the plant is maintained and regularized by the skillful employees to extract the amount of heat with a same ratio that it can regenerate heat down the well in accordance with the conduction flow of rocks.

\section{Conclusion}

There is no doubt in it that Pakistan has got an immense source of thermally high gradient geothermal fields in various part of country. So, there is a strong need that government of Pakistan must consider the geothermal energy as a high potential for the production of electricity to remove the energy crises in a long term planning. At an initial step, the detail engineering survey for the installation of power plants must be conducted to estimate the electric potential for various fields within a country.

There is also need to create awareness about geothermal energy among the nation for the direct utilization to build up the trend likewise of other alternate source of energies. It will be a remarkable achievement to initiate steps among masses for the building of geothermal energy which is considered to be as environment friendly with an exceptionally low carbon effusion.

\section{List of Abbreviation}

$\begin{array}{ll}\text { HPGR } & \text { High Potential Gradient Range } \\ \text { GPP } & \text { Geothermal Power Plant } \\ \text { MW } & \text { Mega Watt } \\ \text { STG } & \text { Surface Temperature Gradient } \\ \text { HDR } & \text { Hot \& Dry Rock } \\ \text { AEDB } & \text { Alternate Energy Development Board }\end{array}$

\section{References}

1. Pakistani wind turbines power [Internet]. [cited 2018 Sep 25]. Available from: https://en.wikipedia.org/wiki/ Wind_power_in_Pakistan.
2. Power shortfall exceeds 6,000MW [Internet]. [cited 2014 Apr 29]. Available from: http://www.dawn.com/news/1102945.

3. Geothermal energy could provide all the energy the world will ever need [Internet]. [cited 2010 Oct 16]. Available from: http://www.renewableenergyworld.com/rea/news/ article/2010/09/geothermal-energy-is-the-solution-forthe-future.

4. Bahadori A, Zendehboudi S, Zahedi G. A review of geothermal energy resources in Australia, Current status and prospects. Renewable Sustain Energy. 2013; 21:29-34. https://doi.org/10.1016/j.rser.2012.12.020

5. Zaigham NA. Renewable hot dry rock geothermal energy source and its potential in Pakistan. Renewable Sustain Energy. 2010; 14(3):1124-29. https://doi.org/10.1016/j.rser. 2009.10.002

6. Mughal MN. Geothermal resources of Pakistan and methods for early stage exploration. Geothermal Training Program, Orkuslof- nun, Grensasvegur, Publication Company: Reykjavik, Iceland; 1998. p. 1-16.

7. Quadri VN, Shuaib M. Hydrocarbon prospects of southern Indus Basin. AAPG Bull publication; 1970. p. 730-47.

8. Abbas T, Bazmi A, Bhutto W, Zahedi G. Greener Energy: Issues and challenges for Pakistan- geothermal energy prospective. Renewable and Sustainable Energy Reviews. 2014; 31:258-69. https://doi.org/10.1016/j.rser.2013.11.043

9. Grant MA, Sorey ML. The compressibility and hydraulic diffusivity of a water-steam flow. Water Resources Research. 1979; 15(3):684-6. https://doi.org/10.1029/ WR015i003p00684

10. Atkinson P, Celati R, Corsi R, Kucuk F, Ramey HJ. Thermodynamic behavior of the Bagnore Geothermal Field. Presented at the Larderello Workshop on Geothermal Resource Assessment and Reservoir Engineering. Geothermics. 1978; 7(2-4):185-208. https://doi.org/10.1016/ 0375-6505(78)90010-X

11. Garg SK, Pritchett JW. Two phase flow in geo-pressured geothermal wells. 3rd Geo-pressured Geothermal Energy Conference, University of Southern Louisiana, Lafayete Louisiana. Energy Conversion 1978; 18(1):45-51. https:// doi.org/10.1016/0013-7480(78)90088-8

12. Scheidegger AE. The physics of flow through porous media. University of Toronto Press, Toronto; 1958. p. 1-236.

13. Grant MA. Two-phase linear geothermal pressure transients-a comparison with single-phase transients. Journal of Science. 1978; 21:355-64.

14. Brown GO. Henry Darcy and the making of a law. Water Resources Research. 2002; 38(7):1106. https://doi. org/10.1029/2001WR000727

15. Carslaw HS, Jaeger JC. Conduction of Heat in Solids. Oxford (2nd Edition). Claredon Press; 1959. p. 1-386.

16. Çengel, Yunus A, Boles MA. Chapter 10: Vapor and combined power cycles. Thermodynamics: An Engineering 
Approach. 7th ed. Boston: McGraw-Hill; 2002. p. 557-89.

17. Mehta VK, Mehta R. Chapter 2: Generating stations. Principles of Power System, Chand Publication: India; 2005. p. 9-32. PMid:16223448 PMCid:PMC1285366

18. Davis AP, Michaelides EE. Geothermal power production from abandoned oil wells. Energy. 2009; 34:866-72. https:// doi.org/10.1016/j.energy.2009.03.017

19. Zhang YJ, Li ZW, Yu ZW, Guo LL, Jin XP, Xu TF. Evaluation of developing an enhanced geothermal heating system in north-east China: Field hydraulic stimulation and heat production forecast. Energy Buildings. 2014; 88:1-14.

20. Pruess K. Enhanced Geothermal System (EGS) using CO2 as working fluid-a novel approach for generating renewable energy with simultaneous sequestration of carbon. Geothermic. 2006; 35:351-67. https://doi.org/10.1016/j. geothermics.2006.08.002

21. Alternative and Renewable Energy Policy [Internet]. [cited 2006 Dec 01]. Available from: https://www.iea.org/ policiesandmeasures/pams/pakistan/name-38075-en.php.
22. Mughal MN. Geological Survey of Pakistan, Geothermal resources of Pakistan and methods for early stage exploration. Geothermal Training Program United Nations University, Report. 1998; 9:1-16.

23. Alternate Energy Development Board, Ministry of Water and Power, Government of Pakistan, Alternate Technologies; 2003.

24. Baloch MH, Kaloi GS, Wang J. Feasible Wind Power Potential from Costal Line of Sindh Pakistan. Research Journal of Applied Sciences, Engineering and Technology. 2015; 10(4):393-400. https://doi.org/10.19026/rjaset.10.2504

25. Shuja TA. Small Geothermal Resources in Pakistan. Geological Survey of Pakistan, Islamabad Geothermic. 1988;17(2/3):461-4.https://doi.org/10.1016/0375-6505(88) 90075-2

26. Geological Survey of Pakistan [Internet]. [cited 2018 Sep 05]. Available from: https://en.wikipedia.org/wiki/ Geological_Survey_of_Pakista.

27. Dipippo R. Geothermal Power Plants-Principles, Application, Case Studies and Environmental Impacts. 2nd Edition. BH Publication Company: Butterworth Hienemann; 2007. 